\title{
Prevalence of physiological and pathological electrocardiographic findings in Hungarian athletes
}

\author{
O Kiss ${ }^{1 *}$, N Sydó $^{1 *}$, P Vargha $^{1}$, E Édes ${ }^{1}$, G Merkely $^{1}$, T Sydó $^{2}$, B Merkely $^{1}$ \\ ${ }^{1}$ Semmelweis University Heart and Vascular Center, Budapest, Hungary \\ ${ }^{2}$ Veszprém Megyei Csolnoky Ferenc Kórház, Veszprém, Hungary
}

Received: July 7, 2014

Accepted after revision: January 27, 2015

\begin{abstract}
In Hungary, ECG is a keystone of routine athletic screening. Its significance is based on simplicity, quickness and high informative value as well as the fact that appearance of pathological ECG signs can precede the formation of structural heart diseases. During screening of healthy athletes, we studied the incidence of athletic ECG changes and pathological ECG abnormalities. Methods: We performed detailed analysis of 12-lead ECG recordings of asymptomatic elite, non-elite and master athletes and controls. Results: 227 athletes (male: 180, age: $27.2 \pm 8.7$ years) and 89 controls (male: 57 , age: $28.1 \pm 6.8$ years) were examined. Benign ECG signs: sinus bradycardia, early repolarization and isolated Voltage criteria of left ventricular hypertrophy were common and more often in athletes compared to controls. Potentially pathological ECG signs: ST- $(6.6 \%$ vs. $1.1 \%, p<0.05)$ and T-wave $(15.0 \%$ vs. $5.6 \%, p<0.05)$ changes and signs of pathological left ventricular hypertrophy $(5.3 \%$ vs. $0 \%, p<0.05)$ occurred more frequently in athletes compared to controls. Conclusions: Signs of pathological left ventricular hypertrophy and repolarization abnormalities are more often in athletes. No structural heart disease could be verified in the background of the disorders. However, athletes having pathological ECG should be kept under tight cardiology control. Exact definition and widespread knowledge of pathological ECG changes is essential in early recognition of high risk athletes.
\end{abstract}

Keywords: ECG, athlete, sudden cardiac death, preparticipation screening, repolarization

Electrocardiographic (ECG) changes in athletes are common and in most cases reflect benign structural and electrical remodelling of the heart due to physiological adaptation to physical training, often referred to as "athlete's heart" $(15,18,19,24)$. In Hungary, ECG is a cornerstone of routine athletic screening. Its significance is based on simplicity, quickness and high informative value as well as on the fact that the appearance of pathological ECG signs can forecast the emergence of structural heart diseases years in advance.

As part of the detailed cardiovascular screening of healthy, asymptomatic athletes, we performed ECG analysis and studied the incidence of physiological, common ECG changes and potentially pathological, training-unrelated ECG abnormalities at Semmelweis University Heart and Vascular Center. The present prospective study aimed to evaluate ECG characteristics of a composite sample of Hungarian athletes.

\footnotetext{
* Orsolya Kiss and Nóra Sydó contributed equally to this work.

Corresponding author: Béla Merkely PhD, DSc, FESC, FACC

Semmelweis University, Heart and Vascular Center, Budapest, Hungary

Városmajor u. 68, H-1122 Budapest, Hungary

Phone: +36-20-460-3575; Fax: +36-1-458-6859; E-mail: titkarsag@kardio.sote.hu
} 


\section{Materials and Methods}

Standard resting 12-lead ECGs were recorded (BTL - 08MT). Detailed ECG analysis was performed using the 2010 recommendations for ECG interpretation of athletes by the European Society of Cardiology (7). In the frame of the extended cardiovascular screening every enrolled person also underwent personal and family history screening, physical examination, laboratory testing, 24-hour Holter monitoring, echocardiography and cardiac MR. Healthy asymptomatic elite, non-elite and master atletes and controls were studied. Our athlete group was composite according to training intensity and frequency. Healthy asymptomatic volunteers not participating in competitive sports composed the control group. Symptomatic individuals with known cardiovascular diseases were excluded from the study.

Ethical approval was obtained from the Central Ethics Committee of Hungary (136971/2011-EKU[443/PI/11.]) and all participants gave informed consent.

\section{Statistical analysis}

Statistical analyses were performed using SPSS 15.0 program package. Age was compared using two-sample $t$-test, while gender and ECG characteristics were compared using Fisher's exact test. Age data are presented as mean $\pm \mathrm{SD}$, categorical data are presented as percentages. $P$-value $<0.05$ was considered to indicate statistical significance.

\section{Results}

\section{Study population}

Standard ECG screening was applied in 227 Caucasian athletes (male: 180, age: $27.2 \pm 8.7$ ). Elite athletes $(n=155)$ including several members of the Hungarian Olympic team, masters $(n=16)$, non-elite athletes $(n=56)$ and 89 controls (male: 57 , age: $28.1 \pm 6.8)$ were examined. No difference was found in age between athletes and controls, but the rate of female gender was higher in controls. Athletes performed various sports, mainly kayaking and canoeing, water polo and rowing (Fig. 1). They were in diverse phases of training, with $51.5 \%$ in training period, $13.2 \%$ in speed up period and $10 \%$ competing.
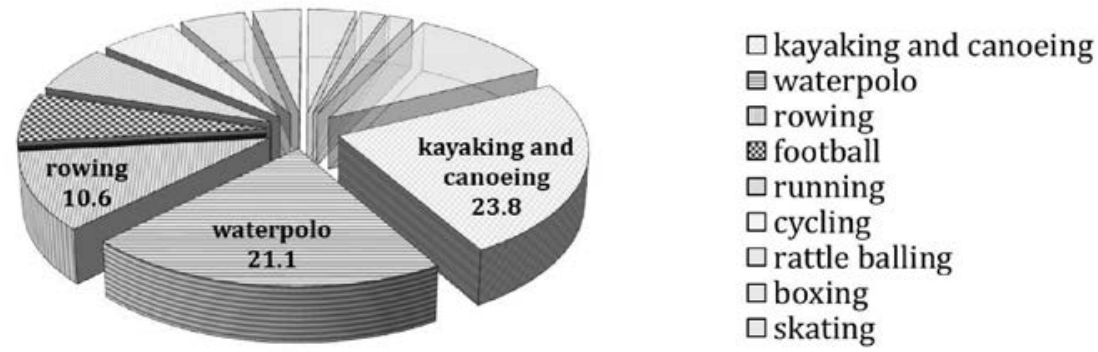

Fig. 1. Sports of the studied athletes 
Training-related physiological ECG findings

According to our results, almost every athlete had at least one training-related ECG sign. Sinus bradycardia, early repolarization and isolated voltage criteria of left ventricular hypertrophy were common and found more often in athletes compared to the control group (Table I, Fig. 2). Incomplete right bundle branch block and $1^{\text {st }}$ degree AV block were often as well, but no differences were found between groups. Marked sinus arrhythmia and transient junctional rhythm also appeared in some athletes and controls (Fig. 3).

\section{Training-unrelated pathological ECG findings}

Some ECG signs considered pathological such as repolarization changes including T-wave abnormalities, ST-segment changes and signs of pathological LVH were found more often in athletes compared to the control group (Table II). In 15\% of the athletes, we recorded T-wave inversion classified as pathological. In most cases, T-wave inversion occurred in adjacent inferior or V1-V3 leads. Out of the ST-segment changes considered training unrelated, about half of them were $\geq 1 \mathrm{~mm}$ horizontal or down-sloping ST-depression in inferior, lateral or precordial leads, some were 1-3.5 mm descending or horizontal ST-elevation in V1-V4 leads, few were 1-2 mm horizontal, flat ST-segment elevation in inferior leads. Left ventricular hypertrophy considered pathological - mostly associated with T-wave inversion - was presented in more than 5\% of the athletes while in no controls (Fig. 4). Signs of right ventricular hypertrophy, atrial enlargement and conduction abnormalities were rare either in athletes or controls with no difference between groups. Left posterior hemiblock, left and right bundle branch blocks were found in some athletes while appeared in no controls (Table II). We found complete right bundle branch block (CRBB, QRS: $120 \mathrm{msec}$ ) in one 22 years old elite male rower and complete left bundle branch block (CLBB, QRS: $160 \mathrm{msec}$ ) in one 16 years old non-elite male scrapper. ECG recordings of a 24 years old elite male canoeist and a 37 years old triathlonist raised the possibility of preexcitation syndromes (Fig. 5).

During the detalied cardiovascular examination, no definite structural heart disease or chanellopathy requiring restriction of sport activity could be verified in any enrolled person.

Table I. Incidence of physiological, training related ECG changes

\begin{tabular}{|l|c|c|c|c|}
\hline \multicolumn{2}{|c|}{ ECG findings } & \multicolumn{2}{c|}{ Athletes } & \multicolumn{2}{c|}{ Controls } \\
\cline { 2 - 5 } & $\boldsymbol{n}$ & $\%$ & $\boldsymbol{n}$ & 13.5 \\
\hline Sinus bradycardia & 116 & $51.1^{* *}$ & 12 & 35.9 \\
\hline Early repolarization & 146 & $64.3^{* *}$ & 32 & 7.8 \\
\hline Left ventricular hypertrophy $^{\times}$ & 52 & $22.9 * *$ & 7 & 31.5 \\
\hline Incomplete right bundle branch block $^{*}$ & 70 & 30.8 & 28 & 6.7 \\
\hline $1^{\text {st }}$ degree AV block & 25 & 11.0 & 6 & 1.1 \\
\hline Junctional rhythm & 2 & 0.9 & 1 & 1 \\
\hline
\end{tabular}

$\left({ }^{\times}\right.$isolated voltage criteria)

$* * p<0.005$ vs. controls 


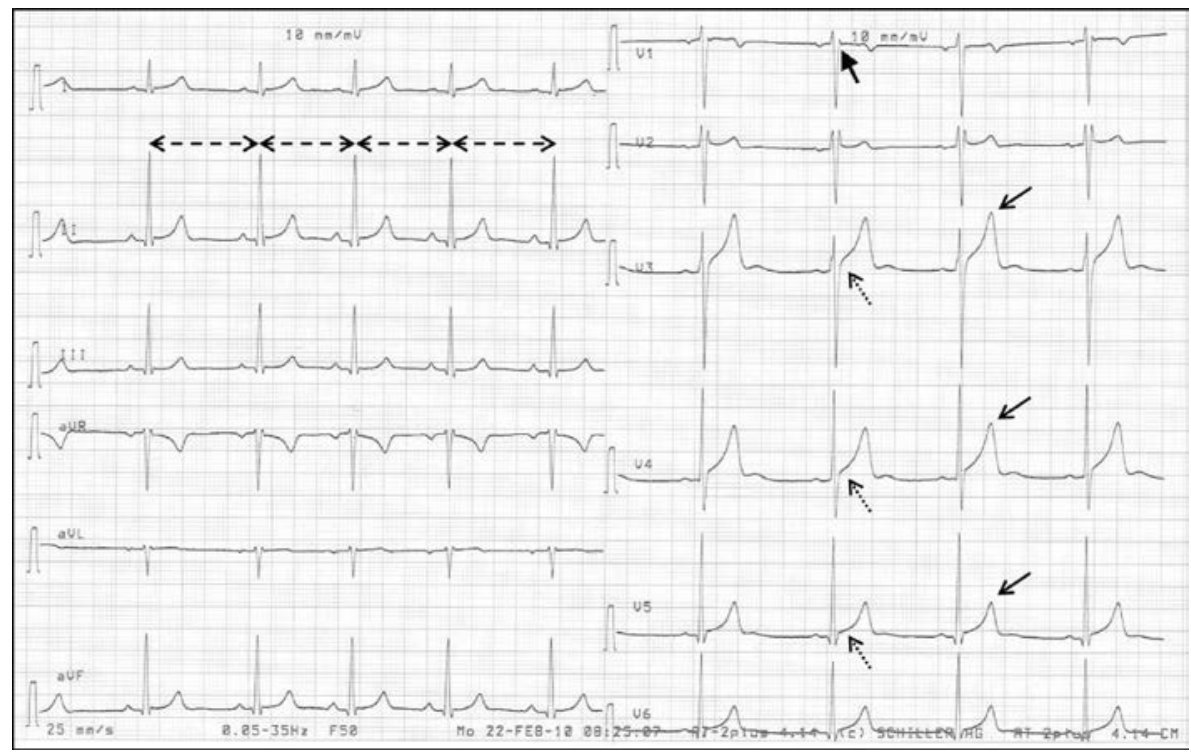

Fig. 2. A characteristic athletic ECG of a 23 years old elite male rower. Sinus bradycardia (mean heart rate: 57/min), sinus arrhythmia (dashed arrows), incomplete right bundle branch block (thick arrow), early repolarization in V3-V5 leads (dotted arrows) and vagotonic T-waves (solid arrows)

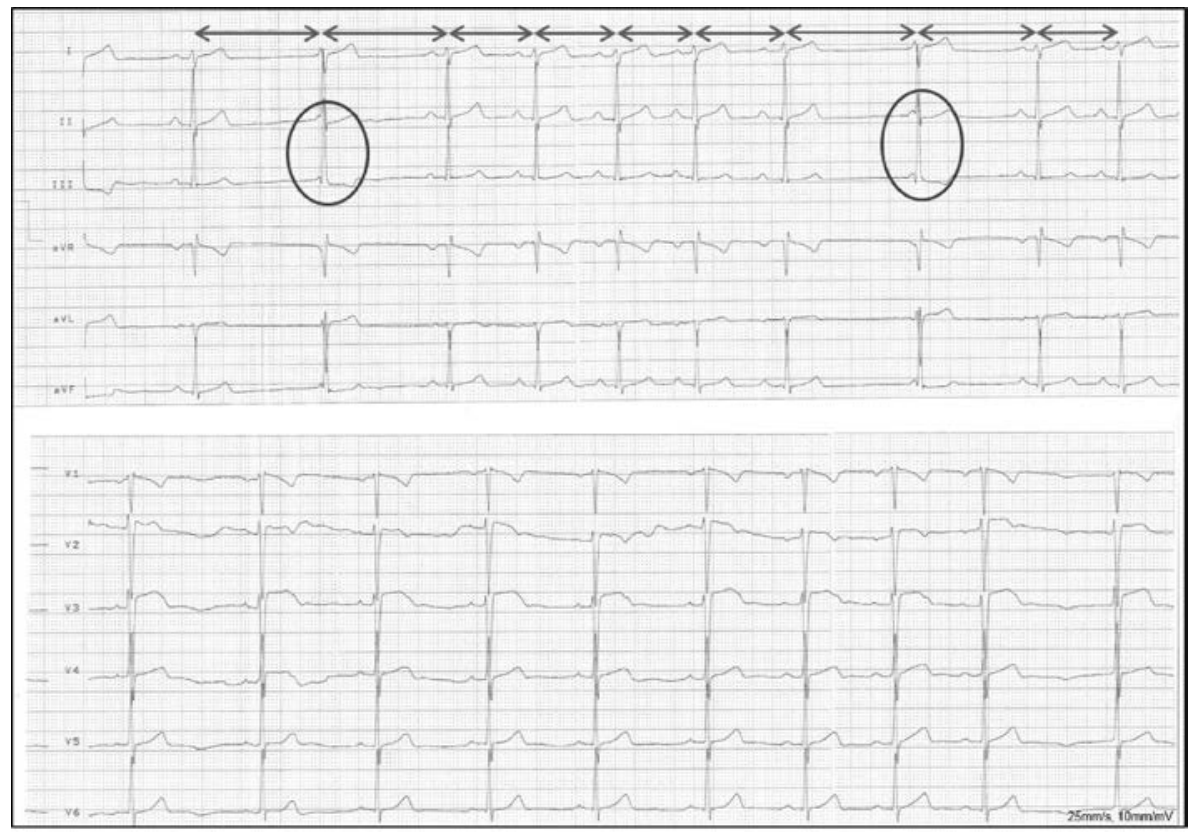

Fig. 3. Resting ECG recording of a 24 years old elite female water polo player. Marked sinus arrhythmia with visible variability of RR intervals (arrows). Junctional beats (circles) follow longer pauses mimicking AV-node disease. Marked, 2-3 mm early repolarization in V3 lead 
Table II. Incidence of pathological, training-unrelated ECG changes

\begin{tabular}{|l|c|c|c|c|}
\hline \multirow{2}{*}{ ECG findings } & \multicolumn{2}{c|}{ Athletes } & \multicolumn{2}{c|}{ Controls } \\
\cline { 2 - 5 } & $\boldsymbol{n}$ & $\%$ & $\boldsymbol{n}$ & \% \\
\hline T-wave changes & 34 & $15.0^{*}$ & 5 & 5.6 \\
\hline ST-segment changes & 15 & $6.6^{*}$ & 1 & 1.1 \\
\hline Pathological left ventricular hypertrophy & 12 & $5.3^{*}$ & - & - \\
\hline Right ventricular hypertrophy & 6 & 2.6 & 1 & 1.1 \\
\hline Atrial hypertrophy & 6 & 2.6 & 1 & 1.1 \\
\hline Left anterior hemiblock & 5 & 2.2 & 1 & 1.1 \\
\hline Left posterior hemiblock & 3 & 1.3 & - & - \\
\hline Delta-wave & 2 & 0.8 & - & - \\
\hline Left bundle branch block & 1 & 0.4 & - & - \\
\hline Right bundle branch block & 1 & 0.4 & - & - \\
\hline
\end{tabular}

$* p<0.05$ vs. controls

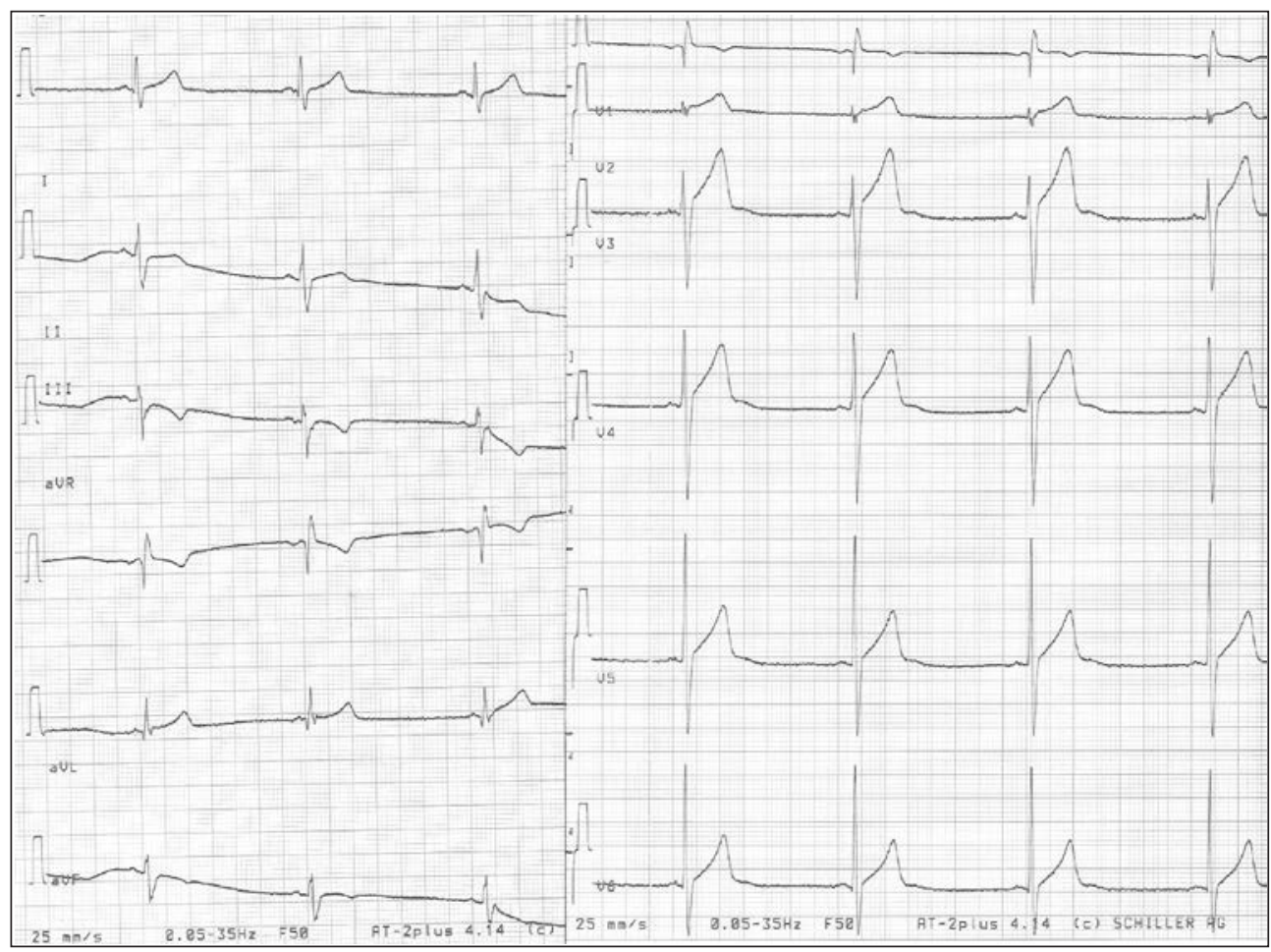

Fig. 4. Left ventricular hypertrophy considered pathological in an asymptomatic 31 years old elite male rower. Marked sinus bradycardia (mean heart rate: $43 / \mathrm{min}$ ), incomplete right bundle branch block, early repolarization and vagotonic T-waves in precordial leads. Cornell-criteria of left ventricular hypertrophy

( $\mathrm{S}$ in $\mathrm{V} 3$ and $\mathrm{R}$ in $\mathrm{aVL} \geq 20 \mathrm{~mm}$ ) and $1-3 \mathrm{~mm} \mathrm{~T}$-wave inversion in leads III and aVF 


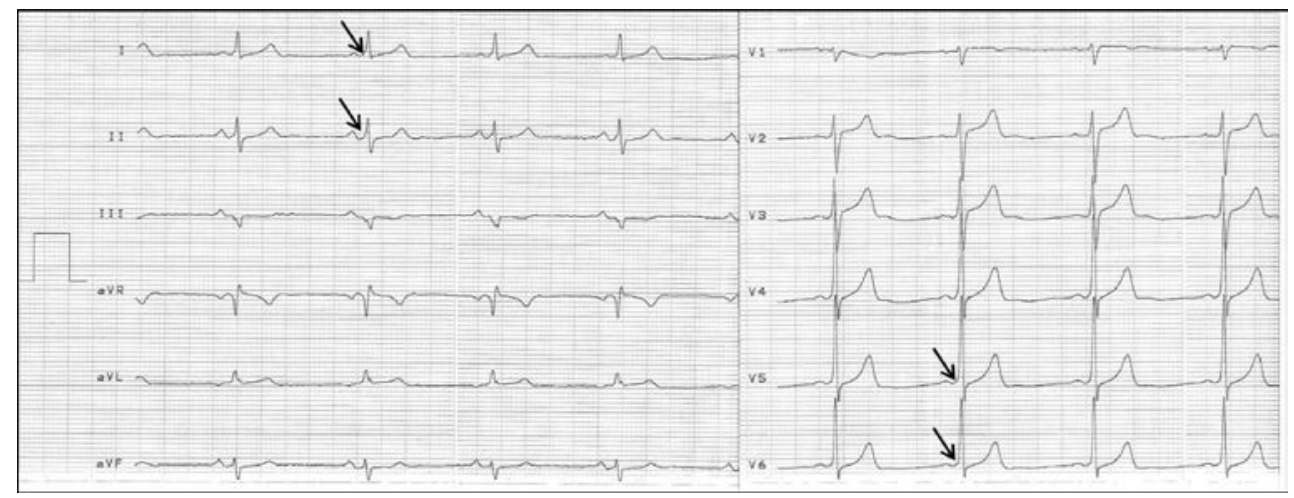

Fig. 5. Sinus bradycardia (mean heart rate: $58 / \mathrm{min}$ ). Delta waves appearing in inferior and lateral leads (arrows), causing slightly widened QRS komplexes $(110 \mathrm{msec})$ and shortened AV-conduction (PQ: $100 \mathrm{msec})$ on the ECG recording of a 24 years old elite male canoeist (arrows)

\section{Discussion}

The screening of athletes with routine electrocardiography requires substantial knowledge in the field of athletic adaptation. Many ECG findings that are considered abnormal in the general population can be normal in athletes as the result of hard physical training. Otherwise, abnormal ECG signs can be the first presentation of cardiovascular diseases that may lead to sudden death of athletes. According to the latest guidelines of the European Society of Cardiology, athletic ECG changes can be devided into two groups: physiological, common, training related ECG findings and pathological, uncommon, training-unrelated ECG abnormalities (7).

As a result of the physiological adaptation, some training-related ECG signs appeared in almost every athlete in our study. Sinus bradycardia was observed in more than $50 \%$ of the athletes in accordance with earlier data, while only in about $10 \%$ of the controls $(4,10)$. As one of the most common training-related ECG finding, sinus bradycardia is most often attributed to high parasympathetic nerve activity (22). However, several researchers question the essential role of vagal tone increase in the bradycardia of athletes. Reduced sympathetic tone or the decrease of intrinsic heart rate due to the remodeling of the sinoatrial node may also contribute to this phenomenon (3).

As a result of enhanced autonomic regulation, marked sinus arrhythmia is also a common ECG finding in athletes. In some cases - mainly when it is associated with junctional beats following longer pauses, this functional AV-dissociation can be deceptive and may also imitate second or third degree AV block, therefore it has to be differentiated from severe AVnode diseases (6). On the standard ECG recordings, no severe AV block was found in our population. Slowed AV conduction presenting as $1^{\text {st }}$ degree AV block was observed in about $10 \%$ of the athletes. Athough, $1^{\text {st }}$ degree AV block is considered to be training-related due to increased parasympathetic and decreased sympathetic tone in athletes (22), no differences were found between athletes and controls.

Incomplete right bundle branch block (IRBB) was found to be present in about $30 \%$ of both groups. In contrast to earlier results, referring to this phenomenon as a result of right ventricular adaptation to exercise, IRBB was not more frequent in athletes compared to controls in our study (11). If IRBB is associated with other ECG abnormalities such as 
repolarization changes or clinical signs or symptoms, structural heart diseases such as ostium secundum atrial septal defect must be excluded. We found this combination in one athlete without any structural heart abnormality. In contrast to IRBB, complete right bundle branch block (CRBB) is categorized as a pathological ECG finding. Athletes with this ECG abnormality must undergo a thorough cardiac examination towards structural diseases, since arrhythmogenic right ventricular cardiomyopathy (ARVC) or Brugada syndrome often manifest as CRBB (7). However, Kim et al. found that increasing QRS duration and CRBB can be a result of more exercise training and right ventricular enlargement in healthy athletes (11). We found the presence of CRBB in a single athlete, detailed cardiac examination did not show any sign of structural heart disease. Another pathological ECG finding, left bundle brach block (LBBB) is uncommon in healthy individuals and it can be a strong and early ECG marker of ischemic or structural heart diseases. We found LBBB in only one athlete without any sign of ischemic or structural heart diseases. Hemiblocks were also rare, there was no difference in the appearance of left anterior and posterior hemiblock between athletes and controls. While left anterior hemiblock is more common and usually appears without evidence of structural heart disease, isolated left posterior hemiblock is very rare and if associated with RBBB it may reflect an increased risk of significant AV block. No bifascicular blocks occurred in our population.

In athletes, WPW-syndrome can lead to sudden cardiac death due to the increased risk of atrial fibrillation and the occurrence of FBI tachycardia (8). Ventricular pre-excitation presented as delta-waves on the standard ECG was registered in two athletes. Frequencydependent marked delta wave broadening was observed on their 24-hour Holter monitoring. Both of them underwent an electrophysiological testing and the accessory fascicules were terminated with radiofrequency catheter ablation and they were permitted to continue sport.

Isolated voltage criteria of left ventricular hypertrophy were observed in more than $1 / 5$ of the athletes, substantially more often than in the control group. Left ventricular hypertrophy was considered pathological if the voltage criteria of left ventricular hypertrophy were associated with at least one additional non-voltage criteria for example left atrial enlargement, left-axis deviation, ST-segment or T-wave abnormalities or pathological Q waves. Mainly because of the appearance of repolarization disorders, signs of pathological LVH were also diagnosed often in athletes and in controls. These changes can also refer to structural heart diseases, which can lead to sudden cardiac death. Primarily, pathological LVH has to be differentiated from hypertrophic cardiomyopathy (HCM), which is the major cause of sudden cardiac death of young athletes in the United States (14). On a characteristic HCM ECG, T-wave inversion in two adjacent leads, deep septal Q-waves, signs of left atrial hypertrophy or arrhythmias (ventricular tachycardia, atrial fibrillation, supraventricular tachycardia) may be observed beside the QRS voltage criteria of left ventricular hypertrophy (21). In the group of athletes with pathological hypertrophy ECG signs, no person was diagnosed with HCM with imaging methods (12).

Referring to the repolarization abnormalities, training related ECG signs of early repolarization were the most frequent changes on the athlete's ECG in our study population. J-point elevation especially in precordial leads has been considered a benign, training related ECG finding (23). In contrast, early repolarization appearing in inferior or lateral leads, particularly if associated with the widening of the terminal part of the QRS called notching or slurring may be associated with sudden cardiac death $(5,9)$. In our study, early repolarization was mainly observed in precordial leads. QRS slurring or notching in inferolateral leads were found in 15 athletes without any other pathological changes during the detailed cardiac examination. 
Although ST-segment elevation due to early repolarization is a common finding in athletic ECG, ST-segment depression is rarely observed and usually concomitant with T-wave inversion (7). Besides the left ventricular hypertrophy, these ECG alterations are also recognized manifestations of HCM. Moreover, ST depression showed correlation with cardiac arrest in HCM patients (16). ST depression can also be a sign of myocardial ischemia due to coronary artery diseases mainly in athletes over 35 years old, or anatomical abnormalities especially in the young (13). In case of down-sloping ST segment elevation in right precordial (V1-V3) leads, Brugada syndrome should also be considered. As compared to athletes, patients with Brugada syndrome have lower Sokolow index, longer QRS duration, the amplitude of maximum ST elevation is greater and does not present beyond right precordial leads and it is rarely associated with giant positive T-waves (2). However, in athletes younger than 16 years old and black athletes the combination of early repolarization and inverted T-waves in precordial leads can be normal variants (17). The differential diagnosis between Brugada-like pattern and athletic normal variant early repolarization is still challenging, but some new ECG criteria were established recently $(1,20)$. In our study, ST segment changes, mainly horizontal ST depression in inferolateral leads were also found more often in athletes compared to controls, whereas no underlying structural heart disease or chanellopathy could be diagnosed.

T-wave changes are considered to be common ECG abnormalities in athletes. According to the ESC recommendation T-wave inversion $\geq 2 \mathrm{~mm}$ in at least two adjacent leads is defined as pathological, however the significance of T-wave inversion $<2 \mathrm{~mm}$ is unclear and also suggested as a potentially pathological sign (7). In our study T-wave inversion $\geq 1 \mathrm{~mm}$ was cathegorized as pathological also in accordance with the Seattle criteria (4). In case of pathological T-wave inversion HCM and Brugada syndrome should be considered as mentioned above. Moreover, ARVC should be excluded. ARVC, the major cause of sudden cardiac death of young athletes in Italy, is typically associated with T-wave inversion in V1V3 leads with epsilon-waves, QRS prolongation or arrhythmias on the ECG. In our athlete group, T-wave inversion was the most common training unrelated ECG finding, observed in $15 \%$ of the athletes, compared to the $5 \%$ of controls. In most of our cases, T-wave inversion was observed in adjacent inferior or right precordial leads without any diagnosed cardiac diseases.

Exact definition and widespread knowledge of ECG is essential in early recognition of high risk athletes. Detalied cardiac examination of athletes with potentially pathological ECG changes is required. In our study of a composite sample of asymptomatic Hungarian athletes, we have not found any structural heart disease, neither in individuals with ECG abnormalities. However, regular cardiovascular follow-up is necessary in all athletes with training-unrelated ECG changes because the appearance of pathological ECG signs can precede the presence of structural heart disease years in advance.

\section{Acknowledgements}

This research was realized in the framework of TÁMOP 4.2.2-08/1/KMR 2008-0004 "Semmelweis Bridge Project - supporting projects of innovative teams from basic research to applied research" followed by TÁMOP 4.2.4. A/1-11-1-2012-0001 "National Excellence Program - Elaborating and operating an inland student and researcher personal support system". The project was subsidized by the European Union and co-financed by state of Hungary. 


\section{REFERENCES}

1. Bayes de Luna A, Brugada J, Baranchuk A, Borggrefe M, Breithardt G, Goldwasser D, Lambiase P, Riera AP, Garcia-Niebla J, Pastore C, Oreto G, McKenna W, Zareba W, Brugada R, Brugada P: Current electrocardiographic criteria for diagnosis of Brugada pattern: a consensus report. J. Electrocardiol. 45, 433-442 (2012)

2. Bianco M, Bria S, Gianfelici A, Sanna N, Palmieri V, Zeppilli P: Does early repolarization in the athlete have analogies with the Brugada syndrome? Eur. Heart J. 22, 504-510 (2001)

3. Boyett MR, D'Souza A, Zhang H, Morris GM, Dobrzynski H, Monfredi O: Viewpoint: is the resting bradycardia in athletes the result of remodeling of the sinoatrial node rather than high vagal tone? J. Appl. Physiol. 114, $1351-1355$ (2013)

4. Brosnan M, La Gerche A, Kalman J, Lo W, Fallon K, Macisaac A, Prior D: The Seattle Criteria increase the specificity of preparticipation ECG screening among elite athletes. Br. J. Sports Med. 48, 1144-1150 (2013)

5. Cappato R, Furlanello F, Giovinazzo V, Infusino T, Lupo P, Pittalis M, Foresti S, De Ambroggi G, Ali H, Bianco E, Riccamboni R, Butera G, Ricci C, Ranucci M, Pelliccia A, De Ambroggi L: J wave, QRS slurring, and ST elevation in athletes with cardiac arrest in the absence of heart disease: marker of risk or innocent bystander? Circ. Arrhythm. Electrophysiol. 3, 305-311 (2010)

6. Corrado D, Biffi A, Basso C, Pelliccia A, Thiene G: 12-lead ECG in the athlete: physiological versus pathological abnormalities. Br. J. Sports Med. 43, 669-676 (2009)

7. Corrado D, Pelliccia A, Heidbuchel H, Sharma S, Link M, Basso C, Biffi A, Buja G, Delise P, Gussac I, Anastasakis A, Borjesson M, Bjornstad HH, Carre F, Deligiannis A, Dugmore D, Fagard R, Hoogsteen J, Mellwig KP, Panhuyzen-Goedkoop N, Solberg E, Vanhees L, Drezner J, Estes NA, 3rd, Iliceto S, Maron BJ, Peidro R, Schwartz PJ, Stein R, Thiene G, Zeppilli P, McKenna WJ: Recommendations for interpretation of 12-lead electrocardiogram in the athlete. Eur. Heart J. 31, 243-259 (2010)

8. Furlanello F, Bertoldi A, Dallago M, Galassi A, Fernando F, Biffi A, Mazzone P, Pappone C, Chierchia S: Atrial fibrillation in elite athletes. J. Cardiovasc. Electrophysiol. 9, S63-S68 (1998)

9. Haissaguerre M, Derval N, Sacher F, Jesel L, Deisenhofer I, de Roy L, Pasquie JL, Nogami A, Babuty D, YliMayry S, De Chillou C, Scanu P, Mabo P, Matsuo S, Probst V, Le Scouarnec S, Defaye P, Schlaepfer J, Rostock T, Lacroix D, Lamaison D, Lavergne T, Aizawa Y, Englund A, Anselme F, O'Neill M, Hocini M, Lim KT, Knecht S, Veenhuyzen GD, Bordachar P, Chauvin M, Jais P, Coureau G, Chene G, Klein GJ, Clementy J: Sudden cardiac arrest associated with early repolarization. N. Engl. J. Med. 358, 2016-2023 (2008)

10. Horvath P, Petrekanits M, Gyore I, Kneffel Z, Varga-Pinter B, Pavlik G: Echocardiographic and spiroergometric data of elite Hungarian female water polo players. Acta Physiol. Hung. 96, 449-457 (2009)

11. Kim JH, Noseworthy PA, McCarty D, Yared K, Weiner R, Wang F, Wood MJ, Hutter AM, Picard MH, Baggish AL: Significance of electrocardiographic right bundle branch block in trained athletes. Am. J. Cardiol. 107, 1083-1089 (2011)

12. Kovacs A, Apor A, Nagy A, Vago H, Toth A, Nagy AI, Kovats T, Sax B, Szeplaki G, Becker D, Merkely B: Left ventricular untwisting in athlete's heart: key role in early diastolic filling? Int. J. Sports Med. 35, 259-264 (2014)

13. Link MS, Mark Estes NA, 3rd: Sudden cardiac death in athletes. Prog. Cardiovasc. Dis. 51, 44-57 (2008)

14. Maron BJ: Sudden death in young athletes. N. Engl. J. Med. 349, 1064-1075 (2003)

15. Maron BJ, Pelliccia A: The heart of trained athletes: cardiac remodeling and the risks of sports, including sudden death. Circulation 114, 1633-1644 (2006)

16. Ostman-Smith I, Wisten A, Nylander E, Bratt EL, Granelli A, Oulhaj A, Ljungstrom E: Electrocardiographic amplitudes: a new risk factor for sudden death in hypertrophic cardiomyopathy. Eur. Heart J. 31, 439-449 (2010)

17. Papadakis M, Carre F, Kervio G, Rawlins J, Panoulas VF, Chandra N, Basavarajaiah S, Carby L, Fonseca T, Sharma S: The prevalence, distribution, and clinical outcomes of electrocardiographic repolarization patterns in male athletes of African/Afro-Caribbean origin. Eur. Heart J. 32, 2304-2313 (2011)

18. Pavlik G, Major Z, Csajagi E, Jeserich M, Kneffel Z: The athlete's heart. Part II: influencing factors on the athlete's heart: types of sports and age (review). Acta Physiol. Hung. 100, 1-27 (2013)

19. Pavlik G, Major Z, Varga-Pinter B, Jeserich M, Kneffel Z: The athlete's heart Part I (Review). Acta Physiol. Hung. 97, 337-353 (2010)

20. Serra G, Baranchuk A, Bayes-De-Luna A, Brugada J, Goldwasser D, Capulzini L, Arazo D, Boraita A, Heras ME, Garcia-Niebla J, Elosua R, Brugada R, Brugada P: New electrocardiographic criteria to differentiate the Type-2 Brugada pattern from electrocardiogram of healthy athletes with r'-wave in leads V1/V2. Europace 16, $1639-1645$ (2014) 
21. Sheikh N, Papadakis M, Malhotra A, Millar L, Dhutia H, Merghani A, Narain R, Wilson M, McKenna W, Sharma S: 89 The electrocardiographic phenotype in athletes with hypertrophic cardiomyopathy: implications for pre-participation cardiovascular evaluation using electrocardiography. Heart 100 Suppl. 3, A51 (2014)

22. Sztajzel J, Jung M, Sievert K, Bayes De Luna A: Cardiac autonomic profile in different sports disciplines during all-day activity. J. Sports Med. Phys. Fitness 48, 495-501 (2008)

23. Tanguturi VK, Noseworthy PA, Newton-Cheh C, Baggish AL: The electrocardiographic early repolarization pattern in athletes: normal variant or sudden death risk factor? Sports Med. 42, 359-366 (2012)

24. Weinstock J, Estes NA, 3rd: The heart of an athlete: black, white, and shades of grey with no gold standard. Circulation 127, 1757-1759 (2013) 